\title{
5 Research Square

\section{Hepatitis B surface antigen positive on pregnancy outcomes and BMI z-score in offspring: a population-based study, China, 2011-2018}

\section{Yan Zhao}

Xiamen Diabetes Institute

Yin-ling Chen ( $\square$ chenyinling6666@163.com )

Xiamen university https://orcid.org/0000-0001-7966-2100

\section{Hai-qu Song}

Xiamen University and Fujian Medical University Affiliated First Hospital

\section{Pei-ying Huang}

Xiamen University and Fujian Medical University Affiliated First Hospital

\section{Li-ying Wang}

Xiamen University and Fujian Medical University Affiliated First Hospital

Wei Liu

Xiamen University and Fujian Medical University Affiliated First Hospital

\section{Bing-kun Huang}

Xiamen University and Fujian Medical University Affiliated First Hospital

\section{Fu-ping Lv}

Xiamen University and Fujian Medical University Affiliated First Hospital

Cao xin Huang

Xiamen Diabetes Institute

\section{Bing Yan}

Xiamen University and Fujian Medical University Affiliated First Hospital

\section{Xue-jun Li}

Xiamen University and Fujian Medical University Affiliated First Hospital

\section{Research article}

Keywords: Pregnant women, HBsAg positive, gestational diabetes mellitus, cesarean delivery, BMI z-score

Posted Date: June 3rd, 2019

DOI: https://doi.org/10.21203/rs.2.10022/v1 
License: (c) (i) This work is licensed under a Creative Commons Attribution 4.0 International License. Read Full License 


\section{Abstract}

Background: Hepatitis B surface antigen (HBsAg) positive leads to pregnancy outcomes and effects on offspring BMI z-score remains unclear in China. We are aim to explore if there is an association among HBsAg positive, BMI z-score, and pregnancy outcomes. Methods: We extracted the characteristic information and pregnancy outcomes of pregnant women, and BMI z-score from 1 to 3 years in offspring from the Medical Birth Registry of Xiamen that registered between 1 March 2011 and 30 March 2018. Results: Pregnant women with HBsAg positive had a higher risk of gestational diabetes mellitus (GDM) $(1.128,1.032-1.232)$, and cesarean delivery $(1.116,1.026-1.213)$. Interestingly, there is no difference between HBsAg positive and offspring BMI z-score (all P > 0.05). Additionally, the GDM women with HBsAg positive had higher incidence of low-for-gestation age (LGA), preterm birth, and cesarean delivery (22.95\%, 9.48\%, and 47.88\%, respectively) (all $\mathrm{P}<0.001$ ). Conclusions: HBsAg positive may be a risk factor of GDM and cesarean delivery. However, HBsAg positive has no effects on offspring BMI z-score. Therefore, women should perform GDM and HBsAg screening before or during pregnancy. As well, a larger follow-up population study should be performed to confirm the association between HBsAg positive and offspring BMI z-score.

\section{Introduction}

Hepatitis B virus infection is a significant public health problem in the world, leading to social burden worldwide and high mortality[ 1]. It is reported that 240 million people are infected with hepatitis B virus, causing six hundred thousand deaths each year[2]. The largest burden of hepatitis B virus exists in China, with 74.6 million people infected[ 3]. An estimated 3.87-9.98\% pregnancy women show hepatitis surface $B$ antigen (HBsAg) positive[ 4]. Moreover, the rate of preterm birth is second largest in China, where 1.17 million babies are born before 37 weeks of gestation. Additionally, incidence of GDM is increasing in the world as obesity becomes more common[5]. Gestational diabetes mellitus (GDM) is characterized as impaired glucose intolerance with first recognition during pregnancy[ 6]. Study showed that 2 to 9 percent of pregnancies suffer from GDM, and is linked to substantial rates of perinatal or maternal complications[ 7]. Furthermore, GDM is related to serious adverse outcomes for maternal and their infants with huge health care burden. The adverse outcomes include birth trauma, fetal macrosomia, caesarean delivery, stillbirth, and preeclampsia[ 8] .

The relationship between hepatitis B virus infection and diabetes mellitus (DM) is still unclear[ 9]. However, the liver plays an important part in glucose metabolism[10]. Several studies investigated the specific relationship between HBsAg positive and GDM in pregnant women. Nevertheless, the results are distinct and even contradictory. Researches show that the association between HBsAg positive and GDM is not identified during pregnancy in Asian and American[4, 11]. However, another study reported that the HBsAg positive increased the risk of GDM in Hong Kong people[ 12]. Hepatitis B virus infection is a major social and economic burden in developing country, especially, in China. However, HBsAg positive in pregnant women is an acknowledged issue that leading to some adverse pregnant outcomes remains unclear. 
However, there are few studies researching the influence of pregnant women not only with GDM but also with HBsAg positive on pregnant outcomes. Meanwhile, there are no researches of associations between HBsAg positive and offspring BMI z-score. Therefore, we performed this study to explore the association among HBsAg positive, offspring BMI z-score, and pregnant outcomes.

\section{Methods}

\section{Patients}

Pregnant women with or without HBsAg positive were included in this study. We extracted information of pregnant women and their offspring who registered the Medical Birth Registry of Xiamen between 1 March 2011 and 30 March 2018, which related to Xiamen citizen health information system. Each citizen has a unique identification number at birth in Xiamen, China.

\section{Registered data}

The included information of the Medical Birth Registry of Xiamen as following: 1) maternal characteristics: age, weight, height, body mass index (BMI), obstetric history, education, family history of hypertension and DM, insulin treatment, systolic blood pressure, diastolic blood pressure, fasting plasma glucose (FPG) and fetus frequency, oral glucose tolerance test (OGTT); 2) birth outcomes: preterm birth, stillbirth, macrosomia, low birth weight, large-for-gestational age (LGA) infant, small-for-gestational age infant, cesarean delivery, and birth weight; 3 ) delivery characteristics: GDM, HBsAg, and gestational weight gain. Meanwhile, BMI was counted by weight $(\mathrm{kg})$ divided by height $(\mathrm{m})$ squared, which divided into four groups ( $18.5 \mathrm{~kg} / \mathrm{m}^{2} ; 18.5-24.9 \mathrm{~kg} / \mathrm{m}^{2} ; 25.0-27.9 \mathrm{~kg} / \mathrm{m}^{2} ; 28 \mathrm{~kg} / \mathrm{m}^{2}$ ). Maternal age was segmented into five groups ( 25 years old; $25-29$ years old; $30-34$ years old; $35-39$ years old; 40 years old). Frequency of delivery was divided into two groups ( 1 times; 2 times). The level of education of maternal was segmented into two groups ( 9-year compulsory education; 9-year compulsory education). OGTT performed at three different time points $(0 \mathrm{~h}, 1 \mathrm{~h}$, and $2 \mathrm{~h}$ ). Besides, the MBRX for children begins with children's birth, including information from newborns to preschool (date of birth, sex, gestational week of birth, weight, Apgar score, family history of diseases, feeding modalities, etc).

\section{Diagnosis criteria of pregnancy outcomes}

GDM diagnosis criteria were referred to the 2014 National Health and Family Planning Commission of the People's Republic of China criteria. When $75 \mathrm{~g}$ OGTT outcomes met or exceeded following plasma glucose value, the pregnancy can diagnosed with GDM. 0 h, $5.1 \mathrm{mmol} / \mathrm{L} ; 1 \mathrm{~h}, 10.0 \mathrm{mmol} / \mathrm{L} ; 2 \mathrm{~h}, 8.5$ $\mathrm{mmol} / \mathrm{L}$. A $75 \mathrm{~g}$ OGTT was performed between the 24th and 28th weeks of gestation for all pregnancy women who did not previously know to suffer from diabetes. The test results were still valid even after 28 weeks. Macrosomia was diagnosed with birth weight more than $4000 \mathrm{~g}$. LGA was ascertained by birth 
weigh more than 90 percentile for gestational age. Small-for-gestation age referred to birth weight less than the 10th percentile for gestational age. What's more, the WHO weight percentile calculator $(3,542$ $437 \mathrm{~g}$ ) was used to count for babies born at 24 to 41 weeks' gestation. Preterm birth was defined as giving birth earlier than 37 weeks of pregnancy.

\section{Statistical analyses}

Statistical analyses were conducted with SPSS 18.0 (SPSS Inc, Chicago, IL, USA). The level of significance for all tests were two-tailed and $P<0.05$. Continuous variables were showed as Mean SD that compared via Student $t$ test or one-way ANOVA. Discontinuous variables were expressed as $\mathrm{n}(\%)$ and compared by Pearson's Chi-square (2) test. Multivariable logistic regression was used for multivariate analyses on account of models containing the factors to assess the association among HBsAg positive during pregnancy, GDM, and pregnancy outcomes.

\section{Ethics statements}

This study was approved by the Review Broad of the First Affiliated Hospital of Xiamen University, and informed consent was not required given the retrospective nature of this study. This study was conducted in accordance with the Helsinki declaration.

\section{Results}

\section{Characteristics of pregnant women with or without HBsAg positive}

Of the 33,437 pregnant women with data information for this study, 3,789 $(11.33 \%)$ pregnant women had hepatitis B virus infection, tested HBsAg positive, and 29,648 (88.67\%) pregnant women with HBsAg negative (Table 1). We found that there was an older age for pregnant women with HBsAg positive compared with negative (29.34.3 vs. 28.94.4, $P<0.001)$. Furthermore, the number of pregnant women with different age indicated that pregnant women were older than 30 years old in HBsAg positive was larger than negative $(42.04 \%$ vs. $37.91 \%, P<0.001)$. In addition, compared with HBsAg negative, the FPG in pregnant women with HBsAg positive was lower (4.70.5 vs. 4.80.5, $P<0.001)$. Moreover, the incidence of OGTT value was abnormal for pregnant women with HBsAg positive were higher than negative (19.98\% vs. $17.75 \%, P<0.001)$. As well, the frequency of fetus more than 2 times, the chance of pregnant women with HBsAg positive was greater than negative $(63.10 \%$ vs. $60.05 \%, P 0.001)$. Although the proportion of pregnant women with HBsAg positive accepted education was less than 9 years was larger than negative $(28.03 \%$ vs. $25.04 \%)$, there was no significance $(P=0.054)$. Besides, compared with $\mathrm{HBsAg}$ negative, there were no significances existed in positive group for BMI, family history of $D M$, and family history of hypertension (all $P>0.05$ ). 


\section{Pregnant outcomes of pregnant women with or without GDM and HBsAg status}

We indicated that the birth weight of pregnant women in GDM-HBsAg+ or NGDM-HBsAg+ group was lighter than GDM-HBsAg- or NGDM-HBsAg- group (3,165.5532.2 or 3,176.8453.6 vs. 3,195.5508.9 or $3,184.3460 .8, P=0.313)$. Whereafter, the proportion of LGA infants in GDM-HBsAg+ group $(22.95 \%)$ or GDM-HBsAg- (22.70\%) group was higher than NGDM-HBsAg+ (16.85\%), and NGDM-HBsAg- (15.87\%) group, $P<0.001$. In addition, the proportion of preterm birth in GDM-HBsAg+ group and GDM-HBsAggroup was larger than NGDM-HBsAg+, and NGDM-HBsAg- group (9.48\% and $7.34 \%$ vs. $5.32 \%$ and $5.18 \%$, $P<0.001)$. Moreover, the percentage of stillbirth in GDM-HBsAg+ group and GDM-HBsAg- group was less than NGDM-HBsAg+ and NGDM-HBsAg-group ( $2.44 \%$ and $3.41 \%$ vs. $4.34 \%$ and $4.24 \%, P=0.036)$. Last but not least, the percentage of cesarean delivery in GDM-HBsAg+ group was highest (47.88\%) compared with GDM-HBsAg- group (43.76\%), NGDM-HBsAg+ group (36.05\%), and NGDM-HBsAg- group (33.70\%). Meanwhile, there was no significance for comparison between GDM-HBsAg status and NGDM-HBsAg status in percentage of small-for-gestation age infant, macrosomia, and low-birth weight (all $P>0.05$ ) (Table 2).

\section{Effects of HBsAg status on pregnant outcomes}

According to univariable logistical regression analysis, we found that the HBsAg positive was risk factor for GDM (OR, 1.157; 95\% Cl, 1.063-1.259) and caesarean delivery (OR, 1.131; 95\% Cl, 1.047-1.222), all $P<$ 0.01 (Table 3). What's more, a multiple variable logistical regression was also used to ensure independent risk factors for the pregnancy outcomes. Results showed that the HBsAg positive was independent risk factor for GDM (OR, 1.128; $95 \% \mathrm{Cl}, 1.032-1.232 ; P<0.001)$ based on adjusted variables including age, $\mathrm{BMI}$, antibiotic, and tocolytic agent. As well, the cesarean delivery $(\mathrm{OR}, 1.116 ; 95 \% \mathrm{Cl}, 1.026-1.213 ; P=$ 0.011 ) was also an independent risk factor after adjusting age, BMI, fetus frequency, insulin, GDM, and antibiotic variables.

\section{Associations between HBsAg positive and offspring BMI z-score from 1 to 3 years}

We compared the offspring BMI z-score according to maternal HBsAg status in different age that indicated there is no association between maternal HBsAg positive and offspring BMI z-score.

Table 4 shows the comparison of children's BMI Z-score from 1 to 3 years of age according to HBsAg status in pregnancy. After adjustment for offspring sex, maternal age, education, and infant feeding, and maternal gestational weight gain (multivariable-adjusted Model 2), offspring exposed to HBsAg positive had no significant mean values of BMI Z-score at 1, 2, and 3 years of age, in comparison with those 
unexposed to $\operatorname{GDM}($ all $P>0.05)$. When introducing maternal pre-pregnancy BMI into the model (multivariable-adjusted Model 3), the differences were still not statistically significant among children of mothers with or without HBsAg positive.

\section{Discussion}

This study is the first research to investigate the association among HBsAg status, offspring BMI z-score, and pregnancy outcomes in China. We found that the GDM women with HBsAg positive who were older than normal pregnancy or non-GDM women with HBsAg negative. The result was consistent with the study, which also showed that the hepatitis B virus infected women were more likely to be older in age [ 13]. Moreover, the research also expressed that number of abnormal blood glucose in pregnancy women with HBsAg positive was higher than negative. A large-sample cross-sectional research revealed that compared with patients with HBsAg negative, the patients with HBsAg positive were more likely to develop DM[14]. In light of the aforementioned outcomes, hepatitis $B$ virus infection might be a potential risk factor for DM. The abnormal blood glucose existed in pregnancy women with HBsAg positive could be explained by several mechanisms. At first, the liver was a key role for regulating glucose homeostasis. Liver damaged by hepatitis B virus might cause a glycometabolism disorder, and inflammatory activities might lead to defective glucose homeostasis. In addition, some studies identified hepatitis B virus infection in pancreas. Hepatitis B virus replications happened in extrahepatic parts, like pancreas, was responsible for causing DM and -cell damage. Secondly, insulin resistance could also be associated with the pathogenesis of hepatogenous diabetes[15]. In the present study, the higher percent for HBsAg positive with abnormal blood glucose might be illustrated by above mechanisms.

In our analysis, we discovered that the BMI of GDM women with HBsAg positive and negative groups were higher than of those without GDM. Compared with normal-weight women, the overweight pregnant women were at the risk of developing GDM[16]. It was a characteristic of GDM that inadequate insulin secretion and insulin resistance, leading to hyperglycemia. Pregnancy women were obesity was a key risk factor for GDM, with a study clarified the OR of developing GDM to be 2.6 for obese women[ 17]. What's more, another research revealed overweight-pregnant women developed GDM was 1.7 times compared with normal weight. A meta-analysis declared developing GDM was incremental 3.6 times in obesity, and 8.6 times in the severely obesity compared with normal-weight women[18]. This was in accord with our result for the weight of GDM women was heavier than non-GDM women. Meanwhile, we found that the percentage of fetus frequency was more than 2 times was largest in GDM women with HBsAg positive compared with other three groups. At present, there are not significant evidences to figure out this finding. We proposed that the multipara with HBsAg positive increased risk for GDM.

The study also suggested that GDM women with HBsAg positive had higher incidence of LGA and stillbirth for infants compared with other groups. For untreated GDM women, their infants were at high risk of LGA, which might be related to delivery injury, respiratory distress, and other factors[19].

Furthermore, women with GDM were more likely to lead to stillbirth[20]. Aforementioned outcomes were in line with the analysis results of this study. 
This study showed that GDM women during pregnancy with HBsAg positive were at a high risk of preterm birth compared with HBsAg negative or non-GDM women. Several large, cohort researches, assessed the association between HBsAg positive and preterm birth[11, 21]. Reddick and colleagues [11] detected that women with HBsAg positive had a higher risk of preterm birth compared with HBsAG negative $(21.9 \%$ vs. $12.1 \%$; OR, 1.65; $95 \% \mathrm{Cl}, 1.3-2.0$ ), after adjusting some variables, such as age, insurance status, medical complications, and race. A Thailand research also found that preterm birth was higher in women with hepatitis Be antigen (HBeAg) positive (13.6\% vs. 8.6\%; OR, 1.250, 95\% Cl, 1.000-1.563)[ 22]. However, a study revealed that they did not discover an identified association between preterm birth and HBsAg positive after adjusting multivariables[21]. Researches performed in China did not discover any relationship between maternal HBsAg positive and preterm birth $[4,23]$. The incompatible results might be associated to study samples, research style, and methods of study. The reasons of preterm birth were multifactorial and intricate. The exact mechanism of preterm birth could not be explained in most cases [ 24], the gather of hepatitis B virus DNA might be used to illustrate the relationship between HBsAg positive and preterm birth, which could initiate the placental inflammatory response [22]. It is required that further researches to make clear the mechanisms of HBsAg positive induced the preterm birth. Interestingly, we observed that not only HBsAg positive affected the percentage of cesarean delivery, preterm birth, and LGA infant, but also GDM also influenced those pregnant outcomes. A study showed that women with GDM had a higher rate of cesarean delivery $(50.8 \%$ vs. $31.8 \%, P<0.001)$, and a higher rate of LGA newborns[25]. Another literature reported that GDM by itself is a risk factor for preterm birth [ 26].

It was showed that HBsAg positive was an independent risk factor for GDM after adjusting multivariable in this analysis $(\mathrm{OR}, 1.124 ; 95 \% \mathrm{Cl}, 1.029-1.228)$. A possible mechanism for women during pregnancy with HBsAg positive developed GDM was that hepatitis B virus infection could cause insulin resistance, potentially in that tumor necrosis factor alpha. Research indicated that tumor necrosis factor alpha and receptor increased in patients with HBsAg positive [27]. As well, serum ferritin concentration was also a risk factor for relationship between GDM and HBsAg positive[28]. The increased serum ferritin level resulted in a higher risk of GDM, because of exposuring to HBsAg to increase insulin resistance. Our research was in accord with previous researches that $\mathrm{HBsAg}$ positive was an independent risk factor for $\operatorname{GDM}[12,28]$. However, study declared that there was no identified association between HBsAg positive and GDM[11]. It was may be lower prevalence of HBsAg positive in those negative researches. Besides, GDM was diagnosed by $75 \mathrm{~g} \mathrm{OGTT} \mathrm{from} \mathrm{24th} \mathrm{to} \mathrm{28th} \mathrm{weeks} \mathrm{of} \mathrm{gestation.} \mathrm{Nevertheless,} \mathrm{other} \mathrm{researches}$ hardly revealed the specific screening methods. The different diagnosis standard of GDM had contributed to the different outcomes. In addition, women with HBsAg positive during pregnancy could increase risk of GDM was still unclear, the above mechanisms might illustrate it at some extent.

Results regarding the HBsAg positive and risk for caesarean delivery from previous researches were not in line with previous researches[22,29]. This study expressed women with HBsAg positive during pregnancy at a higher risk of caesarean delivery. The worries of infection during process of pregnancy, especially, for the pregnancy women with HBsAg positive, although they knew the active and passive immunization is effective for preventing the process of mother-to-infant transmission of hepatitis $B$ virus. 
Therefore, most of they would select caesarean delivery to reduce the risk of HBsAg positive. In China, pregnancy women had the high prevalence of caesarean delivery[30]. To sum up, the HBsAg positive was a risk factor for caesarean delivery. Meanwhile, we found there is no association between HBsAg positive and offspring BMI z-score. This result may result from selective bias and sample sizes.

The strength of this study is the first research to address the association among pregnant women with HBsAg position, offspring BMI z-score, and pregnancy outcomes in Xiamen, where is China' eastern costal economic development zone. Secondly, this is the first study to research effects of pregnant women not only with GDM but also with HBsAg positive on pregnant outcomes. Thirdly, we have included a relatively large sample size that allowed us to adjust the multivariables. However, there are still some limitations. Firstly, as a population-based cohort study, we barely got all associated and desired variables in the Medical Birth Registry of Xiamen. For example, the variables of region and income about pregnant women were missed just like other published researches. Secondly, this study only analyzed the association between HBsAg positive and maternal outcomes, the HBeAg was not examine. Thirdly, there is less follow-up data of offspring BMI z-score. Our further research should focus on the effect of HBeAg on maternal outcomes and expand the follow-up contents and sizes.

\section{Conclusions}

Our research supports that HBsAg positive is a risk factor of GDM and caesarean delivery. In addition, the GDM itself also has an effect on pregnant outcomes, such as preterm birth, LGA infant, and cesarean delivery. It is suggests that early perform hepatitis $B$ virus and diabetes mellitus screening before or during pregnancy is needed that could improve preterm birth and caesarean delivery risk to reduce child mortality. Meanwhile, large and randomized controlled trials are needed to investigate the effect of $\mathrm{HBeAg}$ on the pregnancy outcomes and HBsAg positive on offspring BMI z-score.

\section{Abbreviation}

Abbreviation: HBsAg, hepatitis B surface antigen; HBeAg, hepatitis Be antigen; GDM, gestational diabetes mellitus; DM, diabetes mellitus; LGA, low-for-gestation age; FPG, fasting plasma glucose; OGTT, oral glucose tolerance test; BMI, body mass index; OR, odds ratios; GDM-HBsAg+, gestational diabetes mellitus and hepatitis B surface antigen positive; GDM-HBsAg-, gestational diabetes mellitus and hepatitis B surface antigen negative;

NGDM-HBsAg+, non-gestational diabetes mellitus and hepatitis B surface antigen positive; NGDM-HBsAg-, non-gestational diabetes mellitus and hepatitis B surface antigen negative

\section{Declarations}




\section{Author contributions}

Z Y and C Y-L collected and analyzed data, wrote the first daft, and created the table. S H-Q, H P-Y, W L-Y, and $L W$ designed the study and directed statistical analyses of the data. H B-K, L F-P, and H C-X analyzed and interpreted the data. $L X-J$ and $Y B$ designed the study, and revised the submission. All authors contributed to the discussion, and approved the final manuscript.

\section{Ethics statements}

This study was approved by the Review Broad of the First Affiliated Hospital of Xiamen University, and informed consent was not required given the retrospective nature of this study. This study was conducted in accordance with the Helsinki declaration.

\section{Conflict of interests}

The authors declare that they have no interests.

\section{Funding}

This work was supported by the National Natural Science Foundation of China [grant number: 0070/K16A8035, 0070/K1615020].

\section{Availability of data and materials}

The dataset used and/or analyzed during the this study available from the corresponding author on reasonable request.

\section{Consent for publication}

Not applicable.

\section{References}

1. Saleh-Gargari S, Hantoushzadeh S, Zendehdel N, Jamal A, Aghdam H. The Association of Maternal HBsAg Carrier Status and Perinatal Outcome. Hepat Mon 2009; 9: 180-84.

2. Ott JJ, Stevens GA, Groeger J, Wiersma ST: Global epidemiology of hepatitis B virus infection: new estimates of age-specific HBsAg seroprevalence and endemicity. Vaccine 2012, 30(12):2212-2219. 
3. Wang FS, Fan JG, Zhang Z, Gao B, Wang HY: The global burden of liver disease: the major impact of China. Hepatology 2014, 60(6):2099-2108.

4. Lao TT, Sahota DS, Cheng YK, Law LW, Leung TY: Maternal hepatitis B surface antigen status and incidence of pre-eclampsia. Journal of viral hepatitis 2013, 20(5):343-349.

5. Simmons D (2010) Epidemiologic context of diabetes in pregnancy. In: McCance DR, Maresh M, Sacks DA (eds) A practical manual of diabetes in pregnancy. Blackwell, Oxford, pp 3-17.

6. Metzger BE, Coustan DR: Summary and recommendations of the Fourth International WorkshopConference on Gestational Diabetes Mellitus. The Organizing Committee. Diabetes care 1998, 21 Suppl 2:B161-167.

7. Crowther CA, Hiller JE, Moss JR, McPhee AJ, Jeffries WS, Robinson JS, Australian Carbohydrate Intolerance Study in Pregnant Women Trial G: Effect of treatment of gestational diabetes mellitus on pregnancy outcomes. The New England journal of medicine 2005, 352(24):2477-2486.

8. Poolsup N, Suksomboon N, Amin M: Effect of treatment of gestational diabetes mellitus: a systematic review and meta-analysis. PloS one 2014, 9(3):e92485.

9. Hong YS, Chang Y, Ryu S, Cainzos-Achirica M, Kwon MJ, Zhang Y, Choi Y, Ahn J, Rampal S, Zhao D et al: Hepatitis B and C virus infection and diabetes mellitus: A cohort study. Scientific reports 2017, 7(1):4606.

10. Ashfaq UA, Khalid H: Mechanism of Hepatitis C Virus-Induced Diabetes Mellitus. Critical reviews in eukaryotic gene expression 2017, 27(4):363-371.

11. Reddick KL, Jhaveri R, Gandhi M, James AH, Swamy GK: Pregnancy outcomes associated with viral hepatitis. Journal of viral hepatitis 2011, 18(7):e394-398.

12. Tse KY, Ho LF, Lao T: The impact of maternal HBsAg carrier status on pregnancy outcomes: a casecontrol study. Journal of hepatology 2005, 43(5):771-775.

13. Bajema KL, Stankiewicz Karita HC, Tenforde MW, Hawes SE, Heffron R: Maternal Hepatitis B Infection and Pregnancy Outcomes in the United States: A Population-Based Cohort Study. Open forum infectious diseases 2018, 5(6):ofy134.

14. Schillie SF, Xing J, Murphy TV, Hu DJ: Prevalence of hepatitis B virus infection among persons with diagnosed diabetes mellitus in the United States, 1999-2010. Journal of viral hepatitis 2012, 19(9):674676.

15. Ji D, Cheng J, Dong Z, et al: Screening and identification of genes trans-regulated by HBV pre-S2 protein with CDNA microarray. World Chin J Digestology 2004,12: 1559-1563 (In Chinese).,. 
16. Ovesen P, Rasmussen S, Kesmodel U: Effect of prepregnancy maternal overweight and obesity on pregnancy outcome. Obstetrics and gynecology 2011, 118(2 Pt 1):305-312.

17. Weiss JL, Malone FD, Emig D, Ball RH, Nyberg DA, Comstock CH, Saade G, Eddleman K, Carter SM, Craigo SD et al: Obesity, obstetric complications and cesarean delivery rate--a population-based screening study. American journal of obstetrics and gynecology 2004, 190(4):1091-1097.

18. Chu SY, Callaghan WM, Kim SY, Schmid CH, Lau J, England LJ, Dietz PM: Maternal obesity and risk of gestational diabetes mellitus. Diabetes care 2007, 30(8):2070-2076.

19. Ovesen PG, Jensen DM, Damm P, Rasmussen S, Kesmodel US: Maternal and neonatal outcomes in pregnancies complicated by gestational diabetes. a nation-wide study. The journal of maternal-fetal \& neonatal medicine : the official journal of the European Association of Perinatal Medicine, the Federation of Asia and Oceania Perinatal Societies, the International Society of Perinatal Obstet 2015, 28(14):17201724.

20. Stotland NE, Caughey AB, Breed EM, Escobar GJ: Risk factors and obstetric complications associated with macrosomia. International journal of gynaecology and obstetrics: the official organ of the International Federation of Gynaecology and Obstetrics 2004, 87(3):220-226.

21. Connell LE, Salihu HM, Salemi JL, August EM, Weldeselasse H, Mbah AK: Maternal hepatitis B and hepatitis $\mathrm{C}$ carrier status and perinatal outcomes. Liver international : official journal of the International Association for the Study of the Liver 2011, 31(8):1163-1170.

22. Sirilert S, Traisrisilp K, Sirivatanapa P, Tongsong T: Pregnancy outcomes among chronic carriers of hepatitis B virus. International journal of gynaecology and obstetrics: the official organ of the International Federation of Gynaecology and Obstetrics 2014, 126(2):106-110.

23. Wong S, Chan LY, Yu V, Ho L: Hepatitis B carrier and perinatal outcome in singleton pregnancy. American journal of perinatology 1999, 16(9):485-488.

24. Goldenberg RL, Culhane JF, lams JD, Romero R: Epidemiology and causes of preterm birth. Lancet 2008, 371(9606):75-84.

25. Aviram A, Guy L, Ashwal E, Hiersch L, Yogev Y, Hadar E: Pregnancy outcome in pregnancies complicated with gestational diabetes mellitus and late preterm birth. Diabetes research and clinical practice 2016, 113:198-203.

26. Hedderson MM, Ferrara A, Sacks DA: Gestational diabetes mellitus and lesser degrees of pregnancy hyperglycemia: association with increased risk of spontaneous preterm birth. Obstetrics and gynecology 2003, 102(4):850-856.

27. Sheron N, Lau J, Daniels H, Goka J, Eddleston A, Alexander GJ, Williams R: Increased production of tumour necrosis factor alpha in chronic hepatitis B virus infection. Journal of hepatology 1991, 
12(2):241-245.

28. Lao TT, Tse KY, Chan LY, Tam KF, Ho LF: HBsAg carrier status and the association between gestational diabetes with increased serum ferritin concentration in Chinese women. Diabetes care 2003, 26(11):30113016.

29. Safir A, Levy A, Sikuler E, Sheiner E: Maternal hepatitis B virus or hepatitis C virus carrier status as an independent risk factor for adverse perinatal outcome. Liver international : official journal of the International Association for the Study of the Liver 2010, 30(5):765-770.

30. Lumbiganon P, Laopaiboon M, Gulmezoglu AM, Souza JP, Taneepanichskul S, Ruyan P, Attygalle DE, Shrestha N, Mori R, Nguyen DH et al: Method of delivery and pregnancy outcomes in Asia: the WHO global survey on maternal and perinatal health 2007-08. Lancet 2010, 375(9713):490-499.

\section{Tables}

Table 1. The maternal characteristics between HBsAg-positive and negative groups 


\begin{tabular}{|c|c|c|c|}
\hline & HBsAg negative & HBsAg positive & $P$ value \\
\hline $\mathbf{n}$ & 29,648 & 3,789 & \\
\hline Age, years old & $28.9 \pm 4.4$ & $29.3 \pm 4.3$ & $<0.001^{\#}$ \\
\hline$<25, \mathrm{n}(\%)$ & 3969 (13.39) & $389(10.27)$ & \\
\hline $25-29, \mathrm{n}(\%)$ & $14216(47.95)$ & $1780(46.98)$ & \\
\hline $30-34, \mathrm{n}(\%)$ & 7765 (26.19) & $1117(29.48)$ & \\
\hline $35-39$, n (\%) & $2939(9.91)$ & $401(10.58)$ & $<0.001^{\# \#}$ \\
\hline 口 40, n (\%) & $537(1.81)$ & 75 (1.98) & \\
\hline $\mathrm{BMI}, \mathrm{kg} / \mathrm{m} 2$ & $21.1 \pm 2.9$ & $21.1 \pm 2.9$ & 0.973 \\
\hline$<18.5, \mathrm{n}(\%)$ & 5389 (18.8) & $681(17.97)$ & \\
\hline $18.5-24.9, \mathrm{n}(\%)$ & $19727(66.54)$ & $2531(66.80)$ & \\
\hline $25.0-27.9, \mathrm{n}(\%)$ & 3761 (12.69) & $479(12.64)$ & \\
\hline ૧ 28, n (\%) & $735(2.48)$ & $90(2.38)$ & \\
\hline \multicolumn{4}{|l|}{ Educations } \\
\hline$£ 9$ years, n (\%) & $7869(26.54)$ & $1062(28.03)$ & 0.054 \\
\hline$>9$ years, $\mathrm{n}(\%)$ & 21354 (72.03) & $2673(70.55)$ & \\
\hline Systolic blood pressure, $\mathrm{mmHg}$ & $107.9 \pm 10.6$ & $108.0 \pm 10.7$ & 0.738 \\
\hline Diastolic blood pressure, $\mathrm{mmHg}$ & $65.9 \pm 7.8$ & $65.5 \pm 7.8$ & $0.01^{\#}$ \\
\hline Fasting plasma glucose, mmol/L & $4.8 \pm 0.5$ & $4.7 \pm 0.5$ & $<0.001^{\#}$ \\
\hline \multicolumn{4}{|l|}{ OGTT performed } \\
\hline Fasting value, $\mathrm{mmol} / \mathrm{L}$ & $4.5 \pm 0.4$ & $4.5 \pm 0.4$ & $0.003^{\#}$ \\
\hline 1-h value, $\mathrm{mmol} / \mathrm{L}$ & $7.8 \pm 1.7$ & $8.0 \pm 1.7$ & $<0.001^{\#}$ \\
\hline 2-h value, $\mathrm{mmol} / \mathrm{L}$ & $6.7 \pm 1.4$ & $6.8 \pm 1.5$ & $<0.001^{\#}$ \\
\hline Abnormal result, $\mathbf{n}(\%)$ & $5,263(17.75)$ & $757(19.98)$ & $<0.001^{\# \#}$ \\
\hline Family history of diabetes, n (\%) & $1,074(3.62)$ & $123(3.25)$ & 0.26 \\
\hline Family history of hypertension, $\mathbf{n}(\%)$ & $2,296(7.74)$ & $270(7.13)$ & 0.189 \\
\hline \multicolumn{4}{|l|}{ Number of child births } \\
\hline $1, \mathrm{n}(\%)$ & $11,821(39.87)$ & $1,394(36.79)$ & $<0.001^{\# \#}$ \\
\hline ( 2, n (\%) & $17,805(60.05)$ & $2,391(63.10)$ & \\
\hline
\end{tabular}


Data show as Mean \pm SD and $\mathrm{n}(\%)$, \# indicates $P$ derived from $t$ test, \#\# indicates $P$ derived from $\mathrm{c}^{2}$ test.

Table 2. Maternal and infant characteristics in regard to HBsAg carrier and gestational diabetes mellitus status 


\begin{tabular}{|c|c|c|c|c|c|}
\hline & & \multirow{2}{*}{$\begin{array}{c}P \\
\text { value }^{\mathrm{X}}\end{array}$} \\
\hline & Negative & Positive & Negative & Postive & \\
\hline $\mathbf{n}$ & 24,385 & 3,032 & 5,263 & 757 & \\
\hline \multirow[t]{2}{*}{ Age, years } & $28.4 \pm 4.2$ & $28.8 \pm 4.1^{\mathrm{x}}$ & $30.8 \pm 4.7$ & $31.3 \pm 4.6^{\mathrm{x}}$ & $<$ \\
\hline & & & & & $0.001^{\#}$ \\
\hline$<25, \mathrm{n}(\%)$ & $3,637(14.91)$ & 353 (11.64) & $332(6.31)$ & $36(4.76)$ & \\
\hline $25-29$, n (\%) & $12,252(50.24)$ & $1,532(50.53)$ & 1,964 (37.32) & $248(32.76)$ & \\
\hline $30-34, \mathrm{n}(\%)$ & $6,033(24.74)$ & $826(27.24)$ & 1,732 (32.91) & $291(38.44)$ & \\
\hline 35-39, n (\%) & 1,991 (8.16) & $254(8.38)$ & $948(18.01)$ & 147 (19.42) & $<$ \\
\hline$\square 40, \mathrm{n}(\%)$ & $294(1.21)$ & $44(1.45)$ & $243(4.62)$ & $31(4.10)$ & $0.001^{\# \#}$ \\
\hline \multirow[t]{2}{*}{ BMI, $\mathrm{kg} / \mathrm{m} 2$} & $20.8 \pm 2.8$ & $20.8 \pm 2.7$ & $22.2 \pm 3.2$ & $22.2 \pm 3.3$ & $<$ \\
\hline & & & & & $0.001^{\#}$ \\
\hline$<18.5, \mathrm{n}(\%)$ & $4,844(19.86)$ & 594 (19.59) & 545 (10.36) & 87 (11.49) & \\
\hline 18.5-24.9, n (\%) & $16,422(67.34)$ & $2,051(67.65)$ & $3,305(62.80)$ & $480(63.41)$ & \\
\hline 25.0-27.9, n (\%) & $2,614(10.72)$ & 327 (10.78) & 1,147 (21.79) & 152 (20.08) & \\
\hline ૧ 28, n (\%) & $477(1.96)$ & $53(1.75)$ & $258(4.90)$ & $37(4.89)$ & \\
\hline \multicolumn{6}{|l|}{ Fetus frequency } \\
\hline $1, \mathrm{n}(\%)$ & $10,237(41.98)$ & 1,182 (38.98) & 1,584 (30.10) & $212(28.01)$ & $<$ \\
\hline प 2, n (\%) & $14,130(57.95)$ & 1,847 (60.92) & 3,675 (69.83) & $544(71.86)$ & 0.001 \#\# \\
\hline
\end{tabular}

\section{Insulin treatment}

Yes

No

\section{Infant outcomes}

Birth weight, $g$

Large-for-gestation-age

infant, $\mathrm{n} / \mathrm{N}$ (\%)

Small-for-gestation-age
$3,184.3 \pm 460.8$

$3,145 / 19,822$

(15.87)

$993 / 19,822$
$3,176.8 \pm 453.6$ $421 / 2,499$

(16.85)

$127 / 2,499$
$1,058(20.10) \quad 149$ (19.68)

$4,205(79.90) \quad 608(80.32)$

0.825 


$$
\text { infant, n/N (\%) }
$$

Preterm birth, n/N (\%)

Still birth, n/N (\%)

Macrosomia, n/N (\%)

Low Birth Weight, n/N (\%)

Cesarean delivery, n/N (\%)
(5.01)

$$
1,018 / 19,650
$$

837/19,738

$570 / 19,809$

(2.88)

$1,093 / 19,809$

(5.52)

$6,622 / 19,650$

(33.70)
(5.08)

$132 / 2,481$

$108 / 2,491$

(4.34)

$73 / 2,499$

(2.92)

$133 / 2,499$

$895 / 2,483$

$(36.05)^{\mathrm{j}}$
$(4.32)$

$\begin{array}{ccc}318 / 4,330 & 58 / 612(9.48) & < \\ (7.34) & & 0.001^{\# \#}\end{array}$

$148 / 4,343 \quad 15 / 615(2.44) \quad 0.036^{\# \#}$

176/4,363 26/618 (4.21) 0.07

(4.03)

$304 / 4,363 \quad 40 / 618(6.47) \quad 0.351$

(6.97)

$1,895 / 4,330$

$293 / 612$

(47.88)

(43.76)

Data show as Mean \pm SD and $n,{ }^{\#}$ indicates $P$ derived from $t$ test; ${ }^{\#}$ indicates $P$ derived from $\mathrm{c}^{2}$ test; $\mathrm{x}$ indicates comparison between GDM women with HBsAg positive and negative, $P<0.05$, tested by $t$ test; jindicates comparison between Non-GDM women with HBsAg positive and negative, $P<0.05$, tested by $\mathrm{c}^{2}$ test; $\mathrm{J}$ indicates $\mathrm{P}$ derived from comparison between GDM women with HBsAg status and Non-GDM women with HBsAg status.

Table 3. Gestational diabetes mellitus and perinatal outcomes among women with HBsAg positive and negative 


\begin{tabular}{|c|c|c|c|c|c|c|}
\hline & $\begin{array}{l}\text { HBsAg negative } \\
\text { (n/N, \%) }\end{array}$ & $\begin{array}{l}\text { HBsAg positive } \\
\text { (n/N, \%) }\end{array}$ & $\begin{array}{c}\mathrm{OR}^{\mathrm{J}} \\
(95 \% \mathrm{CI})\end{array}$ & $\begin{array}{c}P \\
\text { value }\end{array}$ & $\begin{array}{c}\mathrm{OR}^{\mathrm{V}} \\
(95 \% \mathrm{CI})\end{array}$ & $\begin{array}{c}P \\
\text { value }\end{array}$ \\
\hline $\begin{array}{l}\text { Gestational } \\
\text { diabetes mellitus }\end{array}$ & $5,263 / 29,648(17.75)$ & $757 / 3,789(19.98)$ & $\begin{array}{c}1.157(1.063- \\
1.259)\end{array}$ & $\begin{array}{c}< \\
0.001\end{array}$ & $\begin{array}{c}1.128 \\
(1.032- \\
1.232)^{\mathrm{a}}\end{array}$ & $<0.001$ \\
\hline $\begin{array}{l}\text { Large-for-gestation } \\
\text { age }\end{array}$ & $4,137 / 24,192(17.10)$ & $\begin{array}{c}564 / 3,122 \\
(18.07)\end{array}$ & $\begin{array}{c}1.069(0.97- \\
1.178)\end{array}$ & 0.179 & NS & NS \\
\hline $\begin{array}{l}\text { Small-for-gestation } \\
\text { age }\end{array}$ & $1,182 / 24,192$ (4.89) & $150 / 3,122(4.80)$ & $\begin{array}{c}0.983(0.826- \\
1.169)\end{array}$ & 0.843 & NS & NS \\
\hline Macrosomia & $746 / 24,172$ (3.09) & $99 / 3,117$ (3.18) & $\begin{array}{c}1.03(0.832- \\
1.275)\end{array}$ & 0.785 & NS & NS \\
\hline Low-birth weight & $1,397 / 24,172$ (5.78) & $173 / 3,117$ (5.55) & $\begin{array}{c}0.958(0.814- \\
1.127)\end{array}$ & 0.605 & NS & NS \\
\hline Preterm birth & $1,336 / 23,980(5.57)$ & $190 / 3,093$ (6.14) & $\begin{array}{c}1.109(0.948- \\
1.298)\end{array}$ & 0.195 & NS & NS \\
\hline Stillbirth & $985 / 24,081$ (4.09) & $123 / 3,106$ (3.96) & $\begin{array}{c}0.967(0.799- \\
1.171)\end{array}$ & 0.73 & NS & NS \\
\hline Cesarean delivery & $8517 / 23,980(35.52)$ & $\begin{array}{c}1,188 / 3,095 \\
(38.38)\end{array}$ & $\begin{array}{c}1.131(1.047- \\
1.222)\end{array}$ & 0.002 & $\begin{array}{c}1.116 \\
(1.026- \\
1.213)^{b}\end{array}$ & 0.011 \\
\hline
\end{tabular}

Data show as $\mathrm{n} / \mathrm{N}$ (\%), J indicates OR derived from univariable logistical regression; $\mathrm{V}$ indicates OR derived from multiple variable logistical regression. ${ }^{\mathrm{a}}$ shows controlled variables as following: age, BMI, and fetus frequency. ${ }^{b}$ indicates controlled variables included age, BMI, fetus frequency, insulin, GDM, and antibiotic. NS indicates no significance. 
Table 4: Comparison of Z-scores for BMI according to maternal HBsAg status in different age

\begin{tabular}{cccc}
\hline BMI Z-score for age & Unexposed to HBsAg+ & Exposed to HBsAg+ & $P$ value \\
\hline $\begin{array}{c}\text { Age 1 year } \\
\text { No participants }\end{array}$ & & & \\
Model 1 & $0.042(0.014)$ & $0.038(0.026)$ & 0.8713 \\
\hline Model 2 & $0.042(0.014)$ & $0.038(0.026)$ & 0.8804 \\
\hline Model 3 & $0.019(0.014)$ & $0.021(0.025)$ & 0.9290 \\
\hline Model 4 & $0.032(0.014)$ & $0.038(0.025)$ & 0.8111 \\
\hline Age 2 year & & & 0.3012 \\
\hline N0. of participants & & & 0.3085 \\
\hline Model 1 & $-0.017(0.020)$ & $0.019(0.036)$ & 0.2500 \\
\hline Model 2 & $-0.017(0.020)$ & $0.183(0.036)$ & 0.2054 \\
\hline Model 3 & $-0.045(0.020)$ & $-0.005(0.035)$ & \\
\hline Model 4 & $-0.032(0.019)$ & $0.011(0.035)$ & \\
\hline Age 3 year & & & 0.8699 \\
\hline N0. of participants & & & 0.8709 \\
\hline Model 1 & $-0.097(0.044)$ & $-0.109(0.077)$ & 0.8332 \\
\hline Model 2 & $-0.097(0.044)$ & $-0.109(0.077)$ & 0.9695 \\
\hline Model 3 & $-0.139(0.044)$ & $-0.155(0.077)$ & $-0.119(0.076)$ \\
\hline
\end{tabular}

Data are mean(SE)

Model 1: adjusted for sex, maternal age, education, and infant feeding;

Model 2: adjusted for covariates in Model 1+ maternal gestational weight gain;

Model 3: adjusted for covariates in Model 2 + maternal pre-pregnancy body mass index;

Model 4: adjusted for covariates in Model 3+birth weight. 